\title{
ERRATA
}

\section{Autonomous Expression of the slo Gene of the Bicistronic nga-slo Operon of Streptococcus pyogenes}

\author{
Dragutin J. Savic, William M. McShan, and Joseph J. Ferretti \\ Department of Microbiology and Immunology, University of Oklahoma Health Sciences Center, Oklahoma City, Oklahoma 73190 \\ Volume 70, no. 5, p. 2730-2733, 2002. Page 2732, column 1, line 7 from bottom: "phoR" should read "pfoR." \\ Page 2732, column 1, lines 6, 4, and 3 from bottom: "phoA" should read "pfoA." \\ Page 2732, column 1, line 4 from bottom: "PhoR" should read "PfoR." \\ Page 2732, column 2, line 4: "phoR" should read "pfoR." \\ Page 2733, column 1, line 17: "phoA" should read "pfoA."
}

\section{Transcript Heterogeneity of the $p 44$ Multigene Family in a Human Granulocytic Ehrlichiosis Agent Transmitted by Ticks}

Ning Zhi, Norio Ohashi, Tomoko Tajima, Jason Mott, Roger W. Stich, Debra Grover, Sam R. Telford III, Quan Lin, and Yasuko Rikihisa

Departments of Veterinary Biosciences and Veterinary Preventive Medicine, College of Veterinary Medicine, The Ohio State University, Columbus, Ohio 43210-1093, and Department of Tropical Public Health, Harvard University School of Public Health, Boston, Massachusetts 02115

Volume 70, no. 3, p. 1175-1184, 2002. Page 1177, column 1, line 1: "P44-7, AF4128122" should read "P44-7, AF412822."

Page 1179, column 2, lines 9 and 10: “. . .lacked a 44-kDa band corresponding to $\mathrm{P} 44-18$ in the $37^{\circ} \mathrm{C}$ sample" should read ". . with a faint $44-\mathrm{kDa}$ band corresponding to $\mathrm{P} 44-18(44-\mathrm{kDa})$ in the $24^{\circ} \mathrm{C}$ sample."

\section{Suppression of Macrophage Activation with CNI-1493 Increases Survival in Infant Rats with Systemic Haemophilus influenzae Infection Carl Granert, ${ }^{1 *}$ Hana Abdalla, ${ }^{1}$ Lars Lindquist,${ }^{1}$ Asim Diab, ${ }^{1}$ Moiz Bakhiet, ${ }^{1}$ Kevin J. Tracey, ${ }^{2}$ and Jan Andersson ${ }^{1}$}

Division of Infectious Diseases, Department of Medicine, Karolinska Institute, Huddinge University Hospital, Stockholm, Sweden, ${ }^{1}$ and Laboratory of Biomedical Science, North Shore University Hospital, Manhasset, New York ${ }^{2}$

Volume 68, no. 9, p. 5329-5334, 2000. Page 5329, the byline should appear as shown above. 